\title{
Association between teaching and support skills and subjective effectiveness of nutritional guidance of registered dietitians at hospitals in a Japanese prefecture
}

\author{
Akiko Tanaka • Masao Kawamura • \\ Kazuko Yamada · Ikuharu Morioka
}

Received: 28 February 2013/Accepted: 1 August 2013/Published online: 28 August 2013

(C) The Japanese Society for Hygiene 2013

\begin{abstract}
Objective The aim of this study is to clarify the association between teaching and support skills and the subjective effectiveness of nutritional guidance of registered dietitians working at hospitals.

Methods We carried out a questionnaire survey of registered dietitians at hospitals in a Japanese prefecture. The utilization of nutritional teaching skills in nutritional guidance was investigated using a self-produced 36-item questionnaire that was designed to be mainly used for diabetic patients in 4 settings: first guidance, first assessment, contemplation stage, and preparation stage. The support skills were evaluated by Kikuchi's Scale of Social Skills: 18 items. The subjective effectiveness of nutritional guidance was defined by the behavioral change of the patients after nutritional guidance as evaluated by a registered dietitian.

Results There were 75 respondents (response rate $46.6 \%$ ). Among the teaching skills, basic skills in an interview were often used, but some related to coaching skills were not in common use in nutritional guidance. Based on the results of principal component analysis, we created a scale for scoring the utilization of nutritional teaching skills in each setting. Multiple linear regression analysis illustrated that high subjective effectiveness of nutritional guidance was associated with high score of
\end{abstract}

A. Tanaka $\cdot$ K. Yamada $\cdot$ I. Morioka $(\bowtie)$

Graduate School of Health and Nursing Science, Wakayama Medical University, Mikazura 580, Wakayama 641-0011, Japan e-mail: moriokai@wakayama-med.ac.jp

A. Tanaka $\cdot$ M. Kawamura

Wakayama Medical University Hospital, Kimiidera 811-1,

Wakayama 641-8510, Japan teaching skills in the preparation stage setting and high score of support skills.

Conclusions These results show that, in addition to frequent use of nutritional teaching skills, improvement of support skills is also necessary to enhance the effectiveness of nutritional guidance.

Keywords Registered dietitian - Nutritional guidance $\cdot$ Effectiveness - Support skills · Multiple linear regression analysis

\section{Introduction}

Due to changes in lifestyle habits, the number of patients with lifestyle-related diseases is increasing. To prevent and/or cure lifestyle-related diseases, it is necessary to change lifestyle habits, such as dietary habit. In Japan, nutritional guidance to counteract lifestyle-related diseases is often provided by a registered dietitian. In such guidance, it is important to motivate patients and encourage appropriate behaviors [1]. To attain this goal, counseling [2-4] and coaching skills [5, 6] have recently been adopted as nutritional teaching skills. Registered dietitians are supposed to utilize nutritional teaching skills practically, e.g., referring to manuals compliant with the Standard Program for Medical Checkup and Health Guidance of the Ministry of Health, Labor, and Welfare (MHLW), Japan [7]. However, it has yet to be revealed how often teaching skills are utilized, and there is no commonly used method to evaluate the frequency of utilization of teaching skills. As a result, the effect of teaching skills on the effectiveness of nutritional guidance is still unclear.

Recently, healthcare practitioners were recognized as one group of human support professionals [8]. If they can 
establish a trusting relationship with a patient when an opportunity for dialog transpires, e.g., a medical interview, the likelihood of more effective treatment increases [9]. Thus, skills to establish a trusting interpersonal relationship as a human support professional (support skills) may also be necessary for registered dietitians to enhance the effectiveness of nutritional guidance. Although it appears important to improve support skills coupled with nutritional teaching skills, there is, at this time, limited information on the relationship between support skills and the effectiveness of nutritional guidance.

The aim of this study is to clarify the association between teaching and support skills and the subjective effectiveness of nutritional guidance of registered dietitians. First, we endeavor to unfold and develop a blueprint for grading the utilization of teaching skills in nutritional guidance. Then, using the results, we clarify the relationship between teaching and support skills and the effectiveness of nutritional guidance.

\section{Subjects and methods}

\section{Subjects}

The subjects targeted in this study were 161 registered dietitians, all of whom worked at hospitals and belonged to the Wakayama Dietetic Association, Wakayama, Japan. A registered dietitian holds a license issued by the MHLW, Japan (Nutritionists Act, Japan). Registered dietitians at hospitals often engage in nutritional guidance, mainly for diabetic patients, to help patients and their families acquire information on nutrition, diet, or healthy eating lifestyles.

\section{Ethical consideration}

The subjects were asked to complete an anonymous questionnaire. We stated clearly on the papers: the aims and methods of the study, protection of personal information and answers, anonymity, that participation was voluntary, that there was no disadvantage to not participating, data usage limits of the survey, and absolute confidentiality of the individual. Submission of the questionnaire by the subject was considered as consent to participate in this study. Therefore, only subjects who agreed with these study purposes were requested to answer and return the questionnaire. A personal envelope for sending back the questionnaire was attached to prevent others from seeing the answers to questions.

The protocol of this study was approved by the Ethical Committee of Wakayama Medical University in December 2011.
Methods

\section{Procedures}

After obtaining the agreement of Wakayama Dietetic Association, we sent an anonymous questionnaire to registered dietitians belonging to the association, which included an explanation of the aims and methods of the study, as well as contact information. The subjects filled in the questionnaire and sent it back to the researchers. Those who had had no experience in providing nutritional guidance for individual diabetic patients in the previous 6 months were asked to send the questionnaire back after filling in only the question regarding experience of nutritional guidance. The survey was carried out in February 2012.

\section{Nutritional teaching skills}

We used a self-produced 36-item questionnaire that was designed to be mainly used for diabetic patients, because many of the patients provided with nutritional guidance mainly suffer from diabetic diseases due to the increase of lifestyle-related diseases. In this study, we define nutritional teaching skills as not providing valuable knowledge, but centering on counseling and coaching. Question items of the questionnaire for analysis were selected based on literature review $[3,10,11]$ and our clinical experience.

The utilization of nutritional teaching skills in nutritional guidance within 6 months was investigated. Because the initial meeting between a registered dietitian and a patient, and when the registered dietitian assesses the patient's conditions for the first time, are important to lead to more effective nutritional guidance, and because the approach from the standpoint of motivating the patient and encouraging appropriate behaviors becomes important in nutritional guidance [1], we considered 4 settings: the first nutritional guidance provided to a diabetic patient (first guidance setting), the first assessment of such a patient's capacity to understand (first assessment setting), nutritional guidance provided to the patient at the stage of contemplation-with the intention of starting healthy behaviors within the following 6 months (contemplation stage setting), and guidance provided to the patient at the stage of preparation-ready to start taking action within the next 30 days (preparation stage setting).

The question items in the first guidance setting consisted of 12 question items mainly necessary for building up a trusting relationship [2]. Those in the first assessment setting were composed of 4 question items that a registered dietitian should check [11]. Those in the contemplation stage setting consisted of 6 question items necessary for arousing a feeling of enthusiasm [10,11], and those in the 
preparation stage setting were composed of 14 question items mainly related to coaching skills $[2,10]$. Using a numerical rating scale, a procedure similar to the visual analog scale, each answer was selected from 0 (no use at all) to 10 (always use). Each selected answer was rated from 0 to 10 points.

To validate the question items, we asked 5 registered dietitians, with teaching careers of 2-35 years, to scrutinize them. Their comments were as follows: All of them answered that the question items were appropriate and effective, and covered a broad range of nutritional teaching skills. However, some of them pointed out question items that had the possibility to mislead the reader. We then corrected the verbal expressions of such question items.

To validate the total scores calculated from the frequency of utilization of nutritional teaching skills, we asked the subjects about their reference to manuals for nutritional guidance at the hospital. Manuals independently compiled by hospitals are often compliant with the skills required for health guidance in the Standard Program for Medical Checkup and Health Guidance, MHLW, Japan [11]. If the registered dietitians refer to such manuals, they have many opportunities to utilize nutritional teaching skills.

\section{Support skills}

The definition of support skills has not yet been established. Here, we define them as skills to establish a trusting interpersonal relationship as a human support professional, measured using Kikuchi's Scale of Social Skills: 18 items (KiSS-18) [12].

KiSS-18 is often used as a scale to overview social skills [13]. This scale consists of 6 subscales: basic skills (3 question items), advanced skills (3 question items), emotional management skills (3 question items), offense management skills (3 question items), stress management skills (3 question items), and planning skills (3 question items) [14]. For each question item, the respondent selected one answer among 5 choices of "Always so," "Generally so," "Hard to say," "Generally not so," and "Always not so." Each selected answer was rated from 1 to 5 points. The points for each answer were summed up as the score. A high score shows a high ability to form amiable interpersonal relationships.

\section{Subjective effectiveness of nutritional guidance}

In this study, the subjective effectiveness was defined by the behavioral change of the patients after nutritional guidance as evaluated by a registered dietitian. We asked the subjects to determine the overall effectiveness by visualizing all the patients, not individual ones, within a couple of months following nutritional guidance. The positive behavioral change of the patients after nutritional guidance was set to 11 levels from 0 (no change at all) to 10 (complete change). The answer selected on the numerical rating scale was rated from 0 to 10 points.

To validate the subjective effectiveness of nutritional guidance, we asked the subjects about the usage of a system to provide continuous nutritional guidance. Some hospitals adopt such a system in which doctors or registered dietitians order the next nutritional guidance to ensure that it is provided to the patient. The effectiveness of continuous guidance has already been reported to cause positive behavioral changes in patients [15].

\section{Statistical analysis}

The number of respondents was 89. Thirteen respondents were excluded from the analysis as they had had no experience in providing nutritional guidance for individual diabetic patients in the previous 6 months, and 1 respondent who had completed less than half of the items in the questionnaire. As a result, 75 respondents served as subjects in this study (effective response rate $46.6 \%$ ).

We used some procedures to achieve the purpose of this study: (1) We clarified the frequency of utilization of nutritional teaching skills. (2) To form total scores using as few question items as possible, principal component analysis was carried out, then we evaluated the reliability of the total scores. (3) We calculated the total scores of the KiSS18. (4) We evaluated the reliability of the subjective effectiveness of nutritional guidance. (5) To find factors relevant to subjective effectiveness, multiple linear regression analysis was used.

Difference in categorical variables was examined by chi-square test and residual analysis. Student's $t$ test was used to compare mean values. Mann-Whitney $U$ test was used to compare median values of subjective effectiveness of nutritional guidance between two groups divided by categorical variables on the characteristics. The Pearson correlation coefficient was calculated to estimate the relationship between two variables.

We sought to use the total score for the purpose of showing the frequencies of utilization of nutritional teaching skills in a comprehensive way. Principal component analysis was carried out to make the total score a composite variable using as few question items as possible.

We calculated Cronbach's alpha, a coefficient of internal consistency, and the reliability coefficient using the Spearman-Brown prediction formula by the spilt-half method (even numbers and odd numbers of identification data) to evaluate the reliability of the variables.

Multiple linear regression analysis (stepwise method) was used to find factors relevant to the subjective 
effectiveness of nutritional guidance. The dependent variable was set to be the points of the subjective effectiveness of nutritional guidance. The independent variables were: age, teaching career, total score of utilization of nutritional teaching skills in each setting, total score of KiSS-18, referring or not to manuals for nutritional guidance, and usage or nonusage of a system to provide continuous nutritional guidance.

Data handling and statistical analyses were carried out by using SPSS version 19.0 (SPSS, Japan). Difference was considered statistically significant for $p<0.05$.

\section{Results}

Characteristics of subjects

Table 1 presents the characteristics of the subjects, $81.3 \%$ of whom were female. The age distribution was wide with mean of 39.2 years [standard deviation (SD) 11.4 years]. Of the subjects, $86.7 \%$ were working in acute (general) hospitals. The mean teaching career was 12.7 years (SD 9.2 years). After qualification acquisition, $32.0 \%$ of subjects had taken a course on communication or coaching skills, while $53.3 \%$ had taken a course on specific health guidance.

\section{Nutritional teaching skills}

The individual mean points of the 36 question items on the utilization of nutritional teaching skills ranged from 4.0 to 9.1 points. They showed normal distribution (ShapiroWilk test, $p>0.05$ ), and their mean was 6.8 (SD 1.1) points. We, therefore, set 7.9 (mean + SD) and 5.7 (mean - SD) as the cut-off points. According to these cutoff points, the utilization of nutritional teaching skills was divided into 3 categories: nutritional teaching skills with points of 8 or more were "high use," those of 6 and 7 were "middle use," and those of 5 or less were "low use."

Table 2 presents the frequencies of utilization of nutritional teaching skills. Judging from the results of residual analysis, the prevalence of "middle use" was significantly lower for all question items, whereas "low use" and "high use" were significantly greater for many question items.

More than two-thirds of the subjects used the following items: "I do not interrupt the patient while he/she is speaking to raise an objection or to criticize him/her" (no dissent or criticism), "I listen to the patient so carefully that I can gauge the sentiment behind his/her words" (attentive listening), "I am the first to introduce myself" (self-introduction), and "I nod to show I am listening to the patient" (showing assent). On the other hand, more than two-thirds of the subjects did not use the item "I begin the
Table 1 Characteristics of subjects

\begin{tabular}{|c|c|c|}
\hline Characteristic & $n$ & $\%$ \\
\hline \multicolumn{3}{|l|}{ Gender } \\
\hline Male & 10 & 13.3 \\
\hline Female & 61 & 81.3 \\
\hline Unknown & 4 & 5.3 \\
\hline \multicolumn{3}{|l|}{ Age, years } \\
\hline $20-29$ & 22 & 29.3 \\
\hline $30-39$ & 16 & 21.3 \\
\hline $40-49$ & 14 & 18.7 \\
\hline $50-$ & 20 & 26.7 \\
\hline Unknown & 3 & 4.0 \\
\hline \multicolumn{3}{|c|}{ Hospital specialty (multiple answers allowed) } \\
\hline Acute (general) hospital & 65 & 86.7 \\
\hline Long-term care hospital & 20 & 26.7 \\
\hline Rehabilitation hospital & 6 & 8.0 \\
\hline Others & 4 & 5.3 \\
\hline Unknown & 2 & 2.7 \\
\hline \multicolumn{3}{|l|}{ Teaching career, years } \\
\hline-5 & 22 & 29.3 \\
\hline $5-9$ & 12 & 16.0 \\
\hline $10-19$ & 19 & 25.3 \\
\hline $20-$ & 19 & 25.3 \\
\hline Unknown & 3 & 4.0 \\
\hline \multicolumn{3}{|c|}{$\begin{array}{l}\text { Taken a course on communication or coaching after qualificatio } \\
\text { acquisition }\end{array}$} \\
\hline Yes & 24 & 32.0 \\
\hline No & 32 & 42.7 \\
\hline Hard to say & 16 & 21.3 \\
\hline Unknown & 3 & 4.0 \\
\hline \multicolumn{3}{|c|}{$\begin{array}{l}\text { Taken a course on specific health guidance after qualification } \\
\text { acquisition }\end{array}$} \\
\hline Yes & 40 & 53.3 \\
\hline No & 30 & 40.0 \\
\hline Hard to say & 3 & 4.0 \\
\hline Unknown & 2 & 2.7 \\
\hline
\end{tabular}

conversation with things unrelated to nutritional guidance, diet, or the patient's disease" (chat prior to guidance) in the first guidance setting.

In the first assessment setting, more than two-thirds of the subjects used the item "I confirm the degree of interest in health action and the motivational level for lifestyle improvement" (confirming interest and motivation).

In the preparation stage setting, more than two-thirds used the items "Making a suggestion, I always comment in an unforceful manner, such as 'How about... ?'” (unforceful question) and "I praise the patient for his/her efforts to attain the goal, as well as for the improvement of examination results" (praise for efforts). On the other hand, more than two-thirds of the subjects did not use the items 
Table 2 Self-produced question items regarding utilization of nutritional teaching skills and frequencies of their utilization in 4 settings

\begin{tabular}{|c|c|c|c|}
\hline & $\begin{array}{l}\text { Low use, } \\
n(\%)\end{array}$ & $\begin{array}{l}\text { Middle use, } \\
n(\%)\end{array}$ & $\begin{array}{l}\text { High use, } \\
n(\%)\end{array}$ \\
\hline \multicolumn{4}{|l|}{ First guidance setting } \\
\hline 1. I enter the nutrition guidance room before the patient does & $24(32.0)^{+}$ & $7(9.3)^{-}$ & $44(58.7)^{+}$ \\
\hline 2. I am the first to introduce myself & $4(5.3)^{-}$ & $3(4.0)^{-}$ & $68(90.7)^{+}$ \\
\hline 3. I begin the conversation with things unrelated to nutritional guidance, diet, or the patient's disease & $51(68.0)^{+}$ & $10(13.3)^{-}$ & $14(18.7)$ \\
\hline 4. I call the patient by his/her own name or in a familiar way during the conversation & $26(34.7)^{+}$ & $8(10.7)^{-}$ & $41(54.7)^{+}$ \\
\hline 5. I listen to the patient so carefully that I can gauge the sentiment behind his/her words & $8(10.7)$ & $13(17.3)^{-}$ & $54(72.0)^{+}$ \\
\hline 6. I repeat the exact words the patient said & $18(24.0)$ & $25(33.3)^{-}$ & $32(42.7)^{+}$ \\
\hline 7. I summarize what the patient said in a way such as saying "You mean that..." afterwards & $24(32.0)^{+}$ & $24(32.0)^{-}$ & $27(36.0)^{+}$ \\
\hline 8. I plainly and briefly convey the sympathy I feel to the patient & $18(24.0)$ & $20(26.7)^{-}$ & $37(49.3)^{+}$ \\
\hline 9. I wait for an answer even when the patient stops making a reply and enters silence & $40(53.3)^{+}$ & $17(22.7)^{-}$ & $18(24.0)$ \\
\hline 10. I nod to show I am listening to the patient & $0(0.0)^{-}$ & $6(8.0)^{-}$ & $69(92.0)^{+}$ \\
\hline 11. I do not interrupt the patient while he/she is speaking to raise an objection or to criticize him/her & $10(13.3)$ & $11(14.7)^{-}$ & $54(72.0)^{+}$ \\
\hline 12. I do not ask yes-no questions but ones to which the respondent can make a free reply & $12(16.0)$ & $16(21.3)^{-}$ & $47(62.7)^{+}$ \\
\hline \multicolumn{4}{|l|}{ First assessment setting } \\
\hline 1. Comprehension & $15(20.0)$ & $17(22.7)^{-}$ & $43(57.3)^{+}$ \\
\hline 2. The degree of interest in health action and the motivational level for lifestyle improvement & $12(16.0)$ & $13(17.3)^{-}$ & $50(66.7)^{+}$ \\
\hline 3. Awareness of the disease & $18(24.0)$ & $15(20.0)^{-}$ & $42(56.0)^{+}$ \\
\hline 4. Confidence in dietary therapy & $22(29.3)^{+}$ & $20(26.7)^{-}$ & $33(44.0)^{+}$ \\
\hline \multicolumn{4}{|l|}{ Contemplation stage setting } \\
\hline 1. I elicit things that are not going well or that the patient does despite himself/herself & $14(18.7)$ & $18(24.0)^{-}$ & $43(57.3)^{+}$ \\
\hline $\begin{array}{l}\text { 2. I ask about things that are going well, what the patient has in their mind, and successful experiences in the } \\
\text { past }\end{array}$ & $12(16.0)$ & $26(34.7)^{-}$ & $37(49.3)^{+}$ \\
\hline $\begin{array}{l}\text { 3. With the emphasis on things that the patient will be able to do, I ask questions such as "How can you } \\
\text { succeed?" instead of "Why can't you do it?" }\end{array}$ & $18(24.0)$ & $17(22.7)^{-}$ & $40(53.3)^{+}$ \\
\hline 4. I ask positive questions such as "What do you want to be in the future?" & $24(32.0)^{+}$ & $24(32.0)^{-}$ & $27(36.0)^{+}$ \\
\hline 5. I introduce other people's success stories on purpose & $35(46.7)^{+}$ & $16(21.3)^{-}$ & $24(32.0)^{+}$ \\
\hline 6. I make the patient think about the advantages and disadvantages of improving lifestyle & $29(38.7)^{+}$ & $25(33.3)^{-}$ & $21(28.0)^{+}$ \\
\hline \multicolumn{4}{|l|}{ Preparation stage setting } \\
\hline 1. I elicit things that are not going well or that the patient does despite himself/herself & $13(17.3)$ & $18(24.0)^{-}$ & $44(58.7)^{+}$ \\
\hline $\begin{array}{l}\text { 2. I ask about things that are going well, what the patient has in their mind, and successful experiences in the } \\
\text { past }\end{array}$ & $13(17.3)$ & $19(25.3)^{-}$ & $43(57.3)^{+}$ \\
\hline 3. I make the patient set his/her specific goal, e.g., what or how many goals the patient would like to achieve & $20(26.7)^{+}$ & $20(26.7)^{-}$ & $35(46.7)^{+}$ \\
\hline 4. I make the patient plan the strategies as to what he/she will be able to do to attain the goal & $27(36.0)^{+}$ & $18(24.0)^{-}$ & $30(40.0)^{+}$ \\
\hline 5. I make the patient plan a plural rather than single strategy & $40(53.3)^{+}$ & $19(25.3)^{-}$ & $16(21.3)$ \\
\hline 6. I ask the patient what I will be able to help him/her with & $51(68.0)^{+}$ & $12(16.0)^{-}$ & $12(16.0)$ \\
\hline 7. I show the patient what I will be able to help him/her with & $38(50.7)^{+}$ & $12(16.0)^{-}$ & $25(33.3)^{+}$ \\
\hline 8. I make a suggestion only after confirming whether the patient accepts me & $38(50.7)^{+}$ & $16(21.3)^{-}$ & $21(28.0)^{+}$ \\
\hline 9. I get permission to make a suggestion & $56(74.7)^{+}$ & $8(10.7)^{-}$ & $11(14.7)$ \\
\hline 10. Making a suggestion, I always comment in an unforceful manner, such as "How about... ?" & $13(17.3)$ & $11(14.7)^{-}$ & $51(68.0)^{+}$ \\
\hline 11. I make a specific suggestion revealing how and what to improve in order to attain the goal & $18(24.0)$ & $20(26.7)^{-}$ & $37(49.3)^{+}$ \\
\hline 12. I make the patient decide exactly when he/she will start what I suggested & $32(42.7)^{+}$ & $17(22.7)^{-}$ & $26(34.7)^{+}$ \\
\hline $\begin{array}{l}\text { 13. For the patient to achieve the end goal, I bring up a subject that makes him/her notice the advantage of } \\
\text { their efforts to take actions }\end{array}$ & $23(30.7)^{+}$ & $23(30.7)^{-}$ & $29(38.7)^{+}$ \\
\hline $\begin{array}{l}\text { 14. I praise the patient for his/her efforts to attain the goal, as well as for the improvement of examination } \\
\text { results }\end{array}$ & $6(8.0)$ & $11(14.7)^{-}$ & $58(77.3)^{+}$ \\
\hline
\end{tabular}

Low use: 0 to 5 points on utilization of nutritional teaching skills

Middle use: 6 or 7 points on utilization of nutritional teaching skills

High use: 8 to 10 points on utilization of nutritional teaching skills

+ /-: more/less than the expected value (residual analysis)

" indicates question items selected to calculate the total score 
Table 3 Results of principal component analysis on question items in the first guidance setting

\begin{tabular}{|c|c|c|c|c|c|}
\hline $\begin{array}{l}\text { Question item in first } \\
\text { guidance setting }\end{array}$ & $\begin{array}{l}\text { First component } \\
\text { (basic } \\
\text { communication) }\end{array}$ & $\begin{array}{l}\text { Second component } \\
\text { (chat prior to guidance) }\end{array}$ & $\begin{array}{l}\text { Third component } \\
\text { (entering a room first) }\end{array}$ & $\begin{array}{l}\text { Fourth component } \\
\text { (compellation) }\end{array}$ & $\begin{array}{l}\text { Fifth component } \\
\text { (self-introduction) }\end{array}$ \\
\hline 8. Empathy & 0.681 & -0.242 & -0.237 & 0.247 & 0.173 \\
\hline 5. Attentive listening & 0.680 & -0.324 & 0.267 & 0.116 & -0.033 \\
\hline 6. Rewording & 0.658 & 0.329 & -0.324 & -0.165 & 0.003 \\
\hline 11. No dissent or criticism & 0.617 & -0.273 & 0.059 & -0.301 & -0.115 \\
\hline 7. Summarizing a matter & 0.575 & 0.418 & -0.426 & -0.253 & 0.063 \\
\hline 12. Open question & 0.553 & -0.415 & 0.316 & 0.014 & 0.346 \\
\hline 10. Showing assent & 0.463 & -0.169 & 0.341 & -0.063 & -0.311 \\
\hline 3. Chat prior to guidance & 0.280 & 0.488 & -0.267 & 0.233 & 0.192 \\
\hline 1. Entering a room first & -0.143 & 0.419 & 0.697 & -0.094 & 0.305 \\
\hline 4. Calling affectionately & 0.321 & 0.393 & 0.286 & 0.607 & 0.219 \\
\hline 9. Silence esteem & 0.279 & 0.484 & 0.406 & -0.496 & -0.056 \\
\hline 2. Self-introduction & 0.231 & 0.287 & 0.161 & 0.341 & -0.757 \\
\hline Proportion (\%) & 24.3 & 13.4 & 12.2 & 8.8 & 8.5 \\
\hline
\end{tabular}

"I get permission to make a suggestion" (permission for suggestion) and "I ask the patient what I will be able to help him/her with" (questions about help).

Table 3 presents the results of the principal component analysis in the first guidance setting. There were 5 components with eigenvalue $\geq 1$. The first component seemed to represent basic communication. The second one was named as chat prior to guidance, and the third one was designated as entering a room first. The fourth one seemed to correspond to compellation. The fifth one was named self-introduction. Based on these results, 7 nutritional teaching items, corresponding to basic communication, were selected out of 12 in the first guidance setting.

In the first assessment setting, there was one component showing the points to be checked. All items were selected. In the contemplation stage setting, there were 2 components. The first one seemed to convey a sense of leading to self-encouragement. The second one was named as discovering an obstacle. For the sense of leading to selfencouragement, 5 items among 6 were selected. In the preparation stage setting, there were 3 components. The first one seemed to represent the process of persuasion by praise and actions. The second one was designated as discovering an obstacle. The third one seemed to correspond to self-esteem. For the process of persuasion by praise and actions, 11 items among 14 were selected.

Using the selected items marked in Table 2, Cronbach's alpha was calculated for each setting. It was 0.733 in the first guidance setting, 0.829 in the first assessment setting, 0.774 in the contemplation stage setting, and 0.892 in the preparation stage setting. They were all significant.

Total scores for the utilization of nutritional teaching skills (scores of teaching skills) were then calculated for each setting. A high score means frequent utilization of nutritional teaching skills in each setting. The scores of teaching skills in the first guidance setting ranged from 29 to 70 . Those in the first assessment setting ranged from 12 to 40 . Those in the contemplation stage setting ranged from 8 to 50 . Those in the preparation stage setting ranged from 0 to 108 .

Those who referred to manuals for nutritional guidance (referring group) composed 27 subjects (36.0\%). The mean score of teaching skills in the first guidance setting was 57.1 in the referring group, being significantly higher $(p=0.020)$ than that $(52.6)$ in the nonreferring group, which was composed of 47 subjects who did not refer to such manuals. The mean score of teaching skills in the first assessment setting in the referring group (31.2) tended to be higher ( $p=0.069)$ than that $(28.1)$ in the nonreferring group, and in the preparation stage setting, that in the referring group (73.6) was significantly higher $(p=0.012)$ than that (61.7) in the nonreferring group.

The subjects were divided into two groups based on the mean value of teaching career: the longer group (35 subjects) and shorter group (37 subjects). The mean scores of teaching skills in the longer group were significantly higher in the contemplation stage setting (longer group 34.7 versus shorter group 30.8) $(p=0.047)$ and in the preparation stage setting (72.2 versus 59.1) $(p=0.004)$.

\section{Support skills}

The mean KiSS-18 score was 61.7 (SD 9.9). By subscale, the value was 10.6 (SD 2.2) for basic skills, 10.3 (SD 2.0) for advanced skills, 10.1 (SD 1.9) for emotional management skills, 9.9 (SD 1.9) for offense management skills, 
Table 4 Correlation coefficients between scores of teaching skills in each setting and KiSS-18
$* p<0.05$

$* * p<0.01$

\begin{tabular}{lllll}
\hline & \multicolumn{4}{l}{ Scores of teaching skills $(n=75)$} \\
\cline { 2 - 5 } & $\begin{array}{l}\text { First } \\
\text { guidance } \\
\text { setting }\end{array}$ & $\begin{array}{l}\text { First } \\
\text { assessment } \\
\text { setting }\end{array}$ & $\begin{array}{l}\text { Contemplation } \\
\text { stage setting }\end{array}$ & $\begin{array}{l}\text { Preparation } \\
\text { stage setting }\end{array}$ \\
\hline Kiss-18 & $0.457^{* *}$ & $0.403^{* *}$ & $0.432^{* *}$ & $0.580^{* *}$ \\
Basic skills & $0.322^{* *}$ & $0.330^{* *}$ & $0.296^{* *}$ & $0.431^{* *}$ \\
Advanced skills & $0.354^{* *}$ & $0.412^{* *}$ & $0.444^{* *}$ & $0.627^{* *}$ \\
Emotional management skills & $0.375^{* *}$ & $0.367^{* *}$ & $0.326^{* *}$ & $0.493^{* *}$ \\
Offense management skills & $0.404^{* *}$ & $0.275^{*}$ & $0.271^{*}$ & $0.463^{* *}$ \\
Stress management skills & $0.417^{* *}$ & $0.254^{*}$ & $0.400^{* *}$ & $0.356^{* *}$ \\
Planning skills & $0.366^{* *}$ & $0.322^{* *}$ & $0.373^{* *}$ & $0.453^{* *}$ \\
\hline
\end{tabular}

10.2 (SD 1.8) for stress management skills, and 10.6 (SD 2.2) for planning skills.

Table 4 presents the relationship between the scores of teaching skills in each setting and the KiSS-18. There were weak $(0.2-0.4)$ to moderate $(0.4-0.7)$ positive relationships. However, strong ( 0.7 and more) positive relationship was not obtained.

Subjective effectiveness of nutritional guidance

Figure 1 shows the distribution of the points of subjective effectiveness of nutritional guidance. Seven points was the most frequent $(28.0 \%)$, followed by 6 points $(24.0 \%)$ and 8 points $(17.3 \%)$. The points did not show normal distribution. The median was 6 (interquartile range: 5-7) points. The two groups, divided by the spilt-half method, showed no difference in the median points of subjective effectiveness. The reliability coefficient calculated by the Spearman-Brown formula was 0.969 .

Those who used a system to provide continuous nutritional guidance (using group) composed 25 subjects $(33.3 \%)$. The median points of subjective effectiveness in the using group (median 7, interquartile range 6-7) was significantly higher than that $(6,5-7)$ in the nonusing group, composed of 47 subjects who did not use such a system.

Factors relevant to subjective effectiveness of nutritional guidance

Table 5 presents the results of multiple linear regression analysis used to find factors relevant to the subjective effectiveness of nutritional guidance. The scores of teaching skills in the preparation stage setting and KiSS-18 were selected as relevant factors. The Durbin-Watson ratio, showing the randomness of residual error, was 1.818 . The variance inflation factors, showing multicollinearity, of both variables were less than 1.5 .

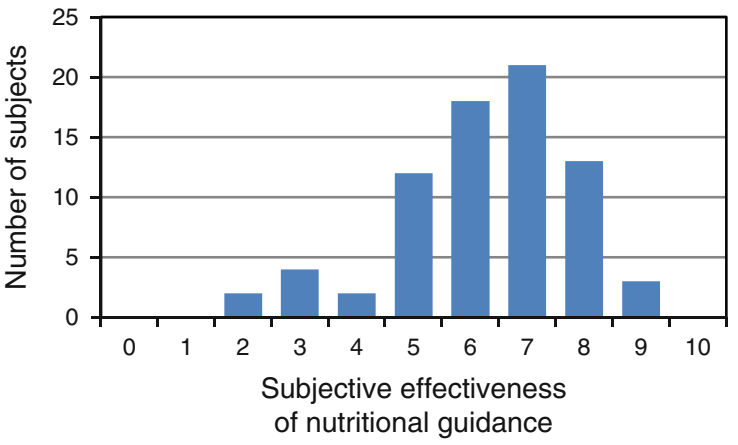

Fig. 1 Distribution of the subjective effectiveness of nutritional guidance

Table 5 Results of multiple linear regression analysis on the subjective effectiveness of nutritional guidance

\begin{tabular}{llll}
\hline Variable & $\begin{array}{l}\text { Regression } \\
\text { coefficient }\end{array}$ & $\begin{array}{l}\text { Standard partial } \\
\text { regression } \\
\text { coefficient }\end{array}$ & $p$ \\
\hline $\begin{array}{l}\text { Total score of KiSS-18 } \\
\begin{array}{l}\text { Scores of teaching skills } \\
\text { in the preparation }\end{array}\end{array}$ & 0.050 & 0.315 & 0.014 \\
$\quad$ stage setting & & 0.288 & 0.024 \\
$R^{2}=0.263, p<0.001$ & & & \\
\end{tabular}

\section{Discussion}

Some teaching skills were often used, but others were not in common use in nutritional guidance. When we calculated the scores of teaching skills for each setting based on the results of principal component analysis, the scores of teaching skills in the preparation stage setting and the KiSS-18 were the factors relevant to the subjective effectiveness of nutritional guidance. 
Nutritional teaching skills

The teaching skills often used on the whole were no dissent or criticism, attentive listening, self-introduction, showing assent, confirming interest and motivation, unforced question, and praise for efforts. These are the basic skills in an interview. The subjects in this study may recognize these skills as elemental principles [16] and often utilize such skills. Furthermore, these skills are easily used because they are independent of the patient's response and can be used at one's own will.

The teaching skills scarcely used overall were chat prior to guidance, permission for suggestion, and questions about help. These are coaching skills [2, 11]. It is desired that such skills be used in a positive manner.

Those who referred to manuals for nutritional guidance, compliant with skills required for health guidance [7], had higher scores of teaching skills in the first guidance setting, first assessment setting, and preparation stage setting. Those who had longer teaching careers had higher scores of teaching skills in the contemplation stage and preparation stage settings. Cronbach's alpha was sufficiently high. Consequently, the scores of teaching skills in this study seem to reflect the utilization of nutritional teaching skills in each setting.

\section{Support skills}

Regarding the subscales of KiSS-18, the mean score of basic skills was 9.5 (SD 1.8) among nurses in a university hospital [14]. That of advanced skills was 10.1 (SD 1.1). That of emotional management skills was 8.8 (SD 1.6). That of offense management skills was 8.9 (SD 1.6). That of stress management skills was 8.8 (SD 1.6). That of planning skills was 9.2 (SD 1.4). Mean scores in this study were significantly higher for emotional management skills, stress management skills, and planning skills (Student's $t$ test). One or more registered dietitian should be assigned to a hospital with more than 100 beds (Medical Care Act, Japan). In fact, only one dietitian is employed in most cases. The dietitian should work comprehensively and have responsibilities. This may result in the higher level of such skills than for nurses who work generally with colleagues at hospitals.

The relationship was not strong between the scores of teaching skills and the KiSS-18. Based on the results, we hypothesized that nutritional teaching skills and support skills independently influence the subjective effectiveness of nutritional guidance, and then we used multiple linear regression analysis. There was no variable showing multicollinearity in the results.
Subjective effectiveness of nutritional guidance

This study aimed to evaluate the effectiveness of nutritional guidance including effects on not only numerical improvement of patient's data, but also changes in his/her behaviors. It is then difficult to obtain numerical evaluation and virtually impossible to ask the patient about the effectiveness of a behavior change. Consequently, we considered the behavioral change of patients after nutritional guidance as evaluated by a registered dietitian as the subjective effectiveness.

We asked the subjects to evaluate the positive behavioral change in patients after nutritional guidance as the subjective effectiveness. The effectiveness of continuous guidance has already been reported to improve HbA1c, causing positive behavioral changes in patients, etc. [15]. Those who used such a system to provide continuous nutritional guidance showed higher points of subjective effectiveness. The reliability coefficient was sufficiently high. Consequently, the points of subjective effectiveness in this study seem to reflect the behavioral change of patients after nutritional guidance.

Scores of teaching skills for each setting and KiSS-18

The scores of teaching skills in the preparation stage setting and the KiSS-18 were the factors that enhanced the subjective effectiveness of nutritional guidance. Although the dependent variable, the subjective effectiveness of nutritional guidance, was not normally distributed, multiple linear regression analysis seemed acceptable because there was no abnormality in the randomness of residual error. The nutritional teaching skills in this study, not providing valuable knowledge but centering on counseling and coaching, may make nutritional guidance effective. This corresponds to the results in earlier reports [17, 18]. At the preparation stage, the patient had completed the preparation to bring about the behavioral change [19]. Registered dietitians may use many teaching skills to take the condition one step further, since skills to set up concrete activities for promoting health are effective at this stage. If successful, they can begin to notice the feeling that the patient's behavior is changing and, subsequently, its effectiveness. Another reason could be that, while it may be difficult to recognize changes in attitudes, it is easy to identify changes in activities.

The KiSS-18 shows the ability to form amiable interpersonal relationships and evaluates overall social skills [13]. Social skills, the ability to step into a relationship with others, and the ability to act appropriately depending on various circumstances may lead to effective nutritional guidance.

In this study, the KiSS-18 was a factor relevant to the subjective effectiveness of nutritional guidance. Social 
skills, including KiSS-18, may be enhanced by social skill training (SST) [20]. SST is now used for new employee training and career education in companies and education systems [21]. SST may enhance social skills and, consequently, the effectiveness of nutritional guidance. The teaching skills at the preparation stage are mainly coaching skills to encourage the patient's decision-making. Mastering these skills is necessary to provide the patient, especially at the preparation stage, with nutritional guidance. Enrolling in courses on nutritional teaching skills and/or specific health guidance is recommended.

There are limitations to the present study. First, the response rate was $46.6 \%$; consequently, less than half of the subjects belonging to the Wakayama Dietetic Association were analyzed in this study, although we sent a reminder notice to the subjects. Second, 13 of 89 (14.6\%) respondents had had no experience in providing nutritional guidance for individual diabetic patients in the previous 6 months. This proportion was more than we had estimated. There must be fewer chances to do so in hospitals mainly for inpatient care, such as long-term care hospitals. Third, the subjects in this study were registered dietitians working at hospitals in one prefecture, a limited area. However, there may be little variation among different areas in duties of registered dietitians. Fourth, the effectiveness of nutritional guidance was subjective. There is a possibility of it being affected by individual beliefs. It is, furthermore, difficult to obtain information regarding how patients individually evaluate the effectiveness of nutritional guidance. Fifth, in the analysis, we hypothesized that teaching skills and support skills independently influence the subjective effectiveness of nutritional guidance. Although the relationship between the two skill sets was not strong, there is the possibility that stronger support skills may increase the frequency of utilization of teaching skills, and thus make the effectiveness higher. It is necessary to examine this possibility in the future.

In conclusion, among teaching skills, basic skills in an interview were often used, but some related to coaching skills were not in common use in nutritional guidance. When we calculated the scores of teaching skills for each setting based on the results of principal component analysis, the scores of teaching skills in the preparation stage setting and the KiSS-18 were factors that enhanced the subjective effectiveness of nutritional guidance. These results show a high probability that, in addition to the utility of nutritional teaching skills, improving support skills is also necessary to enhance the effectiveness of nutritional guidance.

Acknowledgments This study was supported by registered dietitians who provided agreement and responded to our study. This study was partially supported by a Grant-in-aid of Projects Commemorating Mr. Yoshio Fukushima and Mrs. Fusako Tani from the Wakayama Dietetic Association.
Conflict of interest The authors declare that they have no conflict of interest.

\section{References}

1. Saito T. Nutrition counseling. In: Ikeda S, Saito T, Kawano Y, editors. Nutrition education theory. Tokyo: Daiichi Shuppan; 2011. p. 44 (in Japanese).

2. Hamo N, Ito B, Yanagisawa A. Medical coaching lesson. Tokyo: Nanzando; 2010. p. 4 (in Japanese).

3. Step one-learning the basic skills of counseling techniques. http://www.basic-counseling-skills.com/counseling-techniques. html. Accessed 14 Aug 2013.

4. Burnet DL, Elliott LD, Quinn MT, Plaut AJ, Schwartz MA, Chin MH. Preventing diabetes in the clinical setting. J Gen Intern Med. 2006;21(1):84-93.

5. What is health coaching? http://www.satoriholistichealth.com/ what-is-health-coaching.html. Accessed 14 Aug 2013.

6. Vale MJ, Jelinek MV, Best JD, Santamaria JD. Coaching patients with coronary heart disease to achieve the target cholesterol. A method to bridge the gap between evidence-based medicine and the "real world"-randomized controlled trial. J Clin Epidemiol. 2002;55(3):245-52.

7. Health Service Bureau, Ministry of Health, Labour and Welfare. Standard program for medical checkup and health guidance. Tokyo: Ministry of Health, Labour and Welfare; 2007. p. 82-109 (in Japanese).

8. Kohori A. Burnout and emotional burden of human service providers. Bull Grad Sch Educ/Fac Educ Univ Tokyo. 2005;45:133-42 (in Japanese).

9. Inamori R. Evidence-based approach to "active listening" communication training on medical students. Jpn J Hum Welf Stud. 2010;3(1):59-74 (in Japanese).

10. Yanagisawa A. Coaching changes the health guidance!. Osaka: Igaku-Shoin; 2008 (in Japanese).

11. Certification Board for Diabetes Educators in Japan. Psychology and behavior of diabetic patients. In: Certification Board for Diabetes Educators in Japan, editor. Guidebook for candidate of certified diabetes educator in Japan 2010. Tokyo: Medical Review; 2010. p. 97-108 (in Japanese).

12. Kikuchi A. Notes on the researches using KiSS-18. Bull Fac Soc Welf Iwate Prefect Univ. 2004;6(2):41-51 (in Japanese).

13. Kikuchi A. A handbook for measuring KiSS-18. Tokyo: Kawashima Shoten; 2007 (in Japanese).

14. Kikuchi R. Social skill assessment of floor nurses by age: their self-assessment. Jpn J Nurs Adm. 2000;31:123-5 (in Japanese).

15. Mikami H, Sawada Y, Matsuki I, et al. The effect of nutrition counseling for diabetics. Jpn J Asahikawa-Kosei Hosp. 2004;14(2):54-8 (in Japanese).

16. Atagi M. Research on attitudes with guidance on nourishment listening of the counselor. Jpn J Hyg. 2009;64(2):522 (in Japanese).

17. Huffman M. Health coaching: a new and exciting technique to enhance patient self-management and improve outcomes. Home Healthc Nurse. 2007;25(4):271-4.

18. Price A. Using coaching interventions to develop clinical skills. Nurs Stand. 2009;23(44):48-55.

19. Prochaska JO, Di Clemete CC, Norcross JC. In search of how people change applications to addictive behaviors. Am Phychol. 1992;47(9):1102-14.

20. Hondo K. Using SST for improving communication skills of nurses. Jpn J Nurs Adm. 2006;37:409-11 (in Japanese).

21. Goto M, Daibo I. The practice of social skills training during a short-term session for member of society. Jpn J Appl Psychol. 2009;34(2):193-200 (in Japanese). 